\title{
ACARDIUS - ACEPHALUS TWINS: AN UNUSUAL PRESENTATION
}

Nitasha Gupta ${ }^{1}$, Alpana Singh ${ }^{2}$, Shalini Rajaram ${ }^{3}$, Neerja Goel ${ }^{4}$

\section{HOW TO CITE THIS ARTICLE:}

Nitasha Gupta, Alpana Singh, Shalini Rajaram, Neerja Goel. "Acardius - acephalus twins: an unusual presentation". Journal of Evolution of Medical and Dental Sciences 2013; Vol. 2, Issue 47, November 25; Page: 9154-9156.

ABSTRACT: Twin reverse arterial perfusion (TRAP) sequence occurs in 1 in 35,000 births and one percent of monochorionic twins. This condition is fatal for the recipient and carries a high mortality rate for the pump twin. The following case reports a monsterous acardiac co-twin with a normal surviving pump twin.

INTRODUCTION: Acardiac twinning is a rare malformation characterized by a "pump" twin perfusing an anomalous recipient via an artery-to-artery anastomosis, with reversed direction of flow of arterial blood to the perfused fetus leading to total or partial agenesis of the heart and acephaly in the recipient twin with absence of one or more anatomical structures. At least $20 \%$ of the monozygotic co-pump twins can be expected to have congenital anomalies, and $55 \%$ of the pump twins die in the newborn period.(1)

CLINICAL REPORT: A 27 year, unbooked primigravida was admitted in active labour at 39 weeks gestation. Her general physical and systemic examination was normal. On obstetrical examination, the uterus was overdistended with excessive liquor and multiple fetal parts were felt. Ultrasonography revealed a twin pregnancy with both fetuses in breech presentation and an emergency cesarean was performed. The first twin was a normal live born male weighing $2.25 \mathrm{~kg}$. Apgar score was 8 and 9 at 1 and 5 minutes, respectively. The other twin was huge, warranting an extension of the incision in a J-shaped manner. The twin weighed $5.5 \mathrm{~kg}$ (fig. 1). The head and upper extremities were absent. The upper portion of the torso contained soft globular masses with a defect in the anterior abdominal wall. The external male genitalia was incompletely fused. The right foot had one toe whereas left foot had four digits. The lower spinal column and lower leg bones were apparently normal. The placenta was single and weighed $800 \mathrm{gm}$. The histopathology of the placenta confirmed the monochorionic placentation. Minimal autopsy was done which showed absent bony cage and thoracic organs. Neonatal assessment of the first twin including scan of the brain, chest and abdomen was normal. The baby was roomed in with the mother.

DISCUSSION: A variety of acardiac twins have been described based on the degree of cephalic or truncal maldevelopment. (2). Reversed blood flow in the umbilical artery of the acardiac twin causes atrophy of the heart and other organs. The twin with cardiac activity may be hydropic or malformed in $9 \%$ of cases. Perinatal mortality for the pump twin is estimated around $55 \%$. $(3,4)$

First trimester discordance in these cases represent an early manifestation of TRAP sequence. (5) Color Doppler confirms TRAP sequence by showing reversal in the flow direction in umbilical artery of perfused twin, smaller resistive index $(<0.2)$ is associated with poor outcome including cardiac failure and central nervous system hypoperfusion. (6) In our case no antenatal ultrasound was done as she was an unbooked patient and had received no antenatal care. 
Termination of pregnancy should be considered if acardiac twinning is diagnosed at early gestation. Early recognition and active management of the TRAP syndrome with maternal digoxin and indomethacin therapy or invasive procedures (7) can salvage the pump twin to prevent congestive cardiac failure in the pump twin and polyhydramnios in the mother. Risk for congestive heart failure increases to $94 \%$ as the cardiac twin achieves a size more than half the size of the pump twin.

CONCLUSION: TRAP sequence although rare should be suspected in all monochorionic pregnancies. Early diagnosis and timely intervention may help salvage the pump twin.

\section{REFERENCES:}

1. Moore TR, Gale S, Benirschke K, Perinatal utcome of forty-nine pregnancies complicated by acardiac twinnig. Am J Obstet Gynacol 1990; 163:907-12

2. Chen CP, Shih SL, Lui FF, et al. Skeletal deformities of acardius anceps. The gross and imaging features. Pediatr Radiol.1997;27:221-225

3. Van Allen MI, Smith DW, Shepperd TH. Twin reversed arterial perfused (TRAP) sequence: a study of 14 twin pregnancy with acardius. Semin Perinatol 1983;7:285-93.

4. Hanafy A, Peterson CM. Twin reversed arterial perfusion sequenes: Case reports and reviewed of literature. Aust NZ J Obstet Gynecol 1997;37:187-91

5. Kamitomo M, Kouno S, Ibuka k, Oku S, etal. First-trimester findings associated with trap sequence. Fetal diagnther 2004;19 (2):187-90.

6. Dashe JS, Fernandoz CO, Twckler DM. Utility of Doppler velocimetry in predicting outcome in trap sequence. Am J obstet Gynecol 2001;185:135-9.

7. Sepulveda W, Sfier D, Reyes M, Martinez J. Severe polyhydramnios in trap sequence: successful management with intrafetal alcohol ablation of acardiac twin and amnio drainage. Ultrasound Obstet Gynecol. 2000;16:260-263.

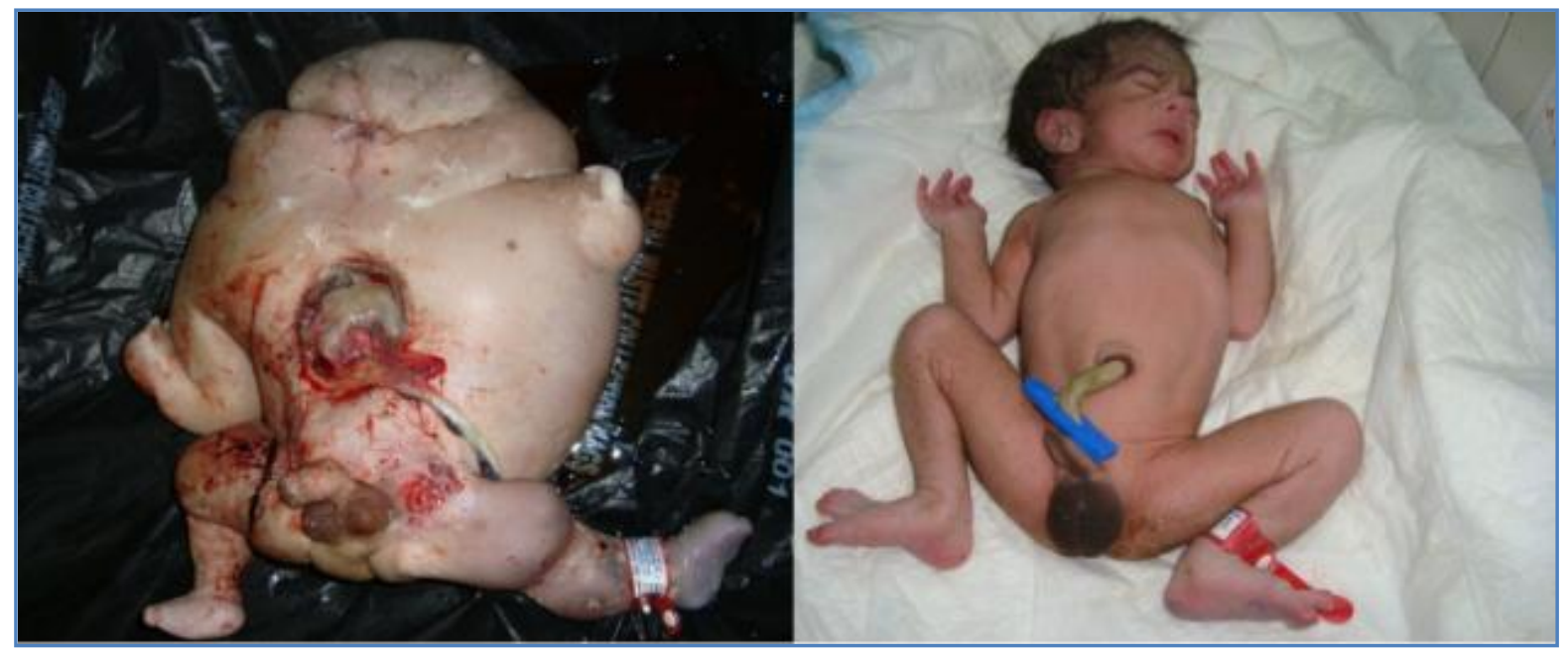

Acardius acephalus with the normal twin.l 


\section{AUTHORS:}

1. Nitasha Gupta

2. Alpana Singh

3. Shalini Rajaram

4. Neerja Goel

\section{PARTICULARS OF CONTRIBUTORS:}

1. Senior Resident, Department of Obstetrics \& Gynaecology, University College of Medical Sciences and Guru Teg Bahadur Hospital, Delhi, India.

2. Lecturer, Department of Obstetrics \& Gynaecology, University College of Medical Sciences and Guru Teg Bahadur Hospital, Delhi, India.

3. Director Professor, Department of Obstetrics \& Gynaecology, University College of Medical Sciences and Guru Teg Bahadur Hospital, Delhi, India.
4. Director Professor, Department of Obstetrics \& Gynaecology, University College of Medical Sciences and Guru Teg Bahadur Hospital, Delhi, India.

\section{NAME ADDRESS EMAIL ID OF THE CORRESPONDING AUTHOR:}

Dr. Nitasha Gupta, Senior Resident, Department of Obstetrics \& Gynaecology, University College of Medical Sciences and Guru Teg Bahadur Hospital, Delhi - 110095, India. Email - nitasha_1980@yahoo.co.in

Date of Submission: 29/10/2013.

Date of Peer Review: 30/10/2013.

Date of Acceptance: 06/11/2013.

Date of Publishing: 20/11/2013 